\title{
Leprosy in the Southern Bahr-el-Ghazal, Anglo-Egyptian Sudan.
}

A. Cruickshank.

7 HE district under review is just north of the French 1 and Belgian Congo frontiers. Its population is 121,000, 1 and consists solely of the Zande or Niam-Niam tribe. For medical work, it is divided into two districts-Tambura and Yambio. The whole area is a " closed district " because of sleeping sickness, but this disease only persists in the Tambura area, and is well under control-a few cases occurring sporadically annually. In the control of sleeping sickness, the whole population, man, woman and child is listed, and is inspected by a medical officer periodically; in highly-infected areas, as often as once monthly and never less than twice a year. This fact made the search for leprosy more easy. 
YAMBIO DisTRICT.

In early 1929, I inspected the entire population of Yambio District-this took four months. The result was :-

No. inspected, 58,136 .

No. of cases of leprosy, 1,556, or 2.8 per cent. Towards the end of the inspection, the natives had tumbled to what we were after, and many of those affected hid themselves, whilst others scarified or burned or blackened their little patches in an endeavour to hide the disease. It was felt, therefore, that the total number infected must be a good deal higher.

The next problem was to find an area large enough to accommodate all these on the settlement system.

After much surveying, an uninhabited tract of bush country was selected, and an area of approximately 30 square miles allocated for the work. Roads were then cut, and watering places selected and cleared of heavy undergrowth to rid them of the tsetse fly. Temporary mud huts for the staff and a temporary hospital were erected.

A start was made by bringing in some 100 advanced and mutilated cases, who were only too glad to be looked after. These were housed, fed, and given special rations of meat and generally well-cared for. Gradually the reputation of the place grew, and slowly the cases we wanted began to trickle in.

On admission, the patient was weighed, his lesions charted, family history taken, given an identification disc with his serial number, and a hoe for cultivation purposes. Any near relative who wanted to stay with him was examined, and if infection free, listed in the "Relatives' Register" and given a differently shaped numbered disc. A plot of land, 1 to 2 acres in extent, with one hut built on it was then allocated. The relatives had to build their own huts on this plot. Two pounds of grain daily, a weekly ration of salt, and seeds for their private cultivations were given. The grain ration ceased when private crops were ripe.

The trickle of admissions slowly grew into a stream, and then into a flood. At one time 50 a day were being admitted, and as each case takes some 15 minutes to register, the task entailed can be imagined, and the hut-builders and road-makers were strained to the utmost to keep pace with the demand.

Within eighteen months of starting, 2,700 cases were admitted, housed and under treatment; by then, resources 
and staff could cope with no more, and it was felt wiser to cease admission and consolidate the position.

A second survey of the population was then made. The outlook by now had so changed, that instead of hiding their leprosy, natives were firing small areas of skin and trying to pass off the resultant hypo-pigmented scar as leprosy!

Including those already admitted, the total number of sufferers was 3,220 , or 5.3 per cent. This total represents every person afflicted with leprosy in the area whose condition could be recognised by careful clinical examination. Therefore, in a year and a half, 84 per cent. of all the cases were under segregation, and this 84 per cent. included all known infectious cases (based on clinical and not bacteriological examinations).

\section{The Settlement.}

There is now some $\mathbf{4 0}$ miles of motor road to which all huts face (see sketch of layout facing p. 9) ; it is diagrammatic, as geometric precision had to give place to geographic irregularity. All buildings were constructed by local paid labour, chiefly inmates and their relatives. Red burnt bricks, hewn iron stone, doors, window frames, etc., were all made by local talent from indigenous material. Carpenters' and blacksmiths' shops are kept at full pressure and are staffed by patients.

Large communal plantations of cassava, pea-nuts, maize, sweet potatoes, rice and bananas are kept up by the inmates themselves. In addition, all of them except the mutilated cases are required to have private crops.

\section{Administration.}

The members of the various tribes in the district which enter the colony have their own section and elect their own headman. This tribal organisation is not interfered with. $\mathrm{He}$ is the representative of the outside paramount Chief. These headmen form the "Lepers' Chiefs' Court," and sit with great pomp and dignity to hear and settle the many cases of marriage tiffs, divorce and adultery, and petty breaches of the peace. The Medical Inspector deals with offences against the Settlement rules, while serious crime, which is rare, is dealt with by the Political Officer of the District. Women, boys and girls, form separate units, and each unit has its "Head-woman, boy or girl," and these "Heads" are responsible for attendances at injections, and must explain absentees and report desertions, etc. 
Every morning of the week, bar Sunday, one unit (approximately 400) parades for injections, salt, and grain ration (the last-named only to new or incapacitated cases). The day following injection, each unit parades for one day's work on the communal cultivations. The other five days of the week are at their own disposal.

Apart from the salutary discipline of a day's work and the parade for treatment, the inmates live their ordinary normal lives, but have better housing conditions, regular issue of salt, a rare issue of meat should a hippo or two be shot, and issues of-root crops during the lean times of the year. There are no modern Josephs among these people and no thought for the morrow. Now that the communal cultivations are bearing, apart from salt, all these patients are self-supporting. The tons of root crops from the cultivations are kept rigidly under control and only issued as occasion demands.

\section{Treatment.}

With such numbers, and a staff who have to cope with sleeping sickness and general medical work as well, mass treatment has been the only thing possible, and alepol by the intravenous route the method of choice, and doses up to a maximum of 10 c.cs. of a 5 per cent. solution are given by this route. The injections are given by trained native orderlies, many of them patients in the non-infectious stage.

Intramuscular, subcutaneous, and intradermal injections are substituted if the veins become thrombosed, but our experience has been that with care, intravenous injections can be continued at weekly intervals (with one month's rest after three months) for a year. We also find that intramuscular and subcutaneous injections, in spite of careful technique, addition of 1 per cent. novocain or other local anæsthetic, and vigorous after-massage, are definitely painful ; sufficiently painful to induce many to absent themselves from injections, and this means loss of the highlyprized salt ration.

Locally trichloracetic acid is used. Ulcers are dressed with hydnocarpus oil. Where advisable, surgical attention is given and large pendulant nodules on ears and noses are removed.

If a case is seen to be going definitely downhill, alepol is stopped, and unless contra-indicated, a course of " 914 " given, plus tonics by mouth, and oil or fat added to the diet if such is available. 
Tambura District.

At the medical headquarters, Source Yubu, a large sleeping sickness settlement of over 1,000 patients has been running for some eight years. Leprosy work was started here in 1927, when 140 cases were admitted. At the end of 1930, a large settlement adjacent to the sleeping sickness one contained 2,123 cases.

A careful survey of the area revealed 3,300 cases of leprosy among a population of 61,000 , or 5.5 per cent. The great majority of these are very early and very mildly infected cases.

In the entire area then, we have 6,500 cases, of whom 4,800 are segregated, and the remainder under observation in their villages and inspected at regular intervals. All infectious cases are under treatment, and when any case outside is found to have gone on to the infectious stage, or if the disease is appreciably advancing, it is immediately taken to one of the settlements and put under treatment.

\section{The Present Situation.}

All who are suffering from leprosy in the district are now known and registered.

Approximately 75 per cent. of them are in settlements and under supervision and treatment.

The untreated 25 per cent. are in the non-infective stages of the disease.

In Tambura (Source Yubu) settlement, highly-infectious (chiefly C3) cases are further segregated by being completely separated from their relatives and housed in a special camp. In Yambio such cases are not specially separated. The incidence among relatives in these settlements is being carefully watched and the comparison of results in these two areas should yield instructive information.

Of those under treatment, 80 per cent. in Tambura and 65 per cent. in Yambio are of the earliest types $-C_{1}$ and $N_{1}$.

From careful analysis of all those segregated, it is obvious, especially in Tambura district, that in the majority of cases leprosy is a self-arresting disease before any permanent damage (apart from slight hypopigmentation of the skin) has occurred. Untreated, only a small portion of cases go on to the later stages. The virulence of the disease here seems low, but the incidence very high.

Is the incidence higher than usual only because it has been possible to make such a minute and careful examination of the entire population? 
Is the virulence low because the resistance of the individual in normal years remains fairly high, due to a reasonably good and varied diet, although it is a diet too rich in carbohydrates, and too low in proteins and fat ?

It is too premature in the history of these settlements to say with authority what the results of treatment are, but I venture to make the following generalisations :-

(1) The resistance of early, apparently self-arrested cases can be maintained.

(2) In many active early cases (I think of low virulence) the progress of the disease can be arrested or at least slowed down.

(3) In many advanced cases, chiefly $\mathrm{C}_{2}, \mathrm{~N}_{1}-\mathrm{C}_{2}$, nothing seems to prevent the onward march of the disease.

(4) In advanced cases-not necessarily mutilated cases-chiefly of the nodular $\mathrm{C}_{3}$ type, treatment seems to have very little effect.

(5) In some $N_{2}$ cases with active trophic changes, the resolution of the disease can be hastened, often preventing further mutilation-this, in itself, is a great thing.

It must be admitted that a small number of spectacular "cures" have occurred, where either the nodules of a $\mathrm{C}_{; 3}$ case have completely scarred up, or where a body almost covered with great red-raised coalescing patches swarming with mycobacteria has returned to almost normal, but I have yet to be convinced that this was due to treatment -I mean, specific treatment by the injection of hydnocarpus derivatives.

In the light of the foregoing remarks, I promulgate the following opinions regarding leprosy in this area :-

(a) That only definitely infectious cases should be segregated and given active routine injection treatment.

(b) That all early cases should be watched, and immediately signs of advance occur, be given active treatment, preferably dispensary treatment outside.

(c) That far more can be done both prophylactically and curatively by measures devoted to treating all other disease, by improving housing conditions and raising social standards and, above all, securing an adequate, varied and plentiful food supply-in short, by raising the resistance.

Though these are my personal conclusions, because so many observers all over the world have reported so favourably on hydnocarpus in early cases I do not feel justified in discontinuing treatment even in apparently 

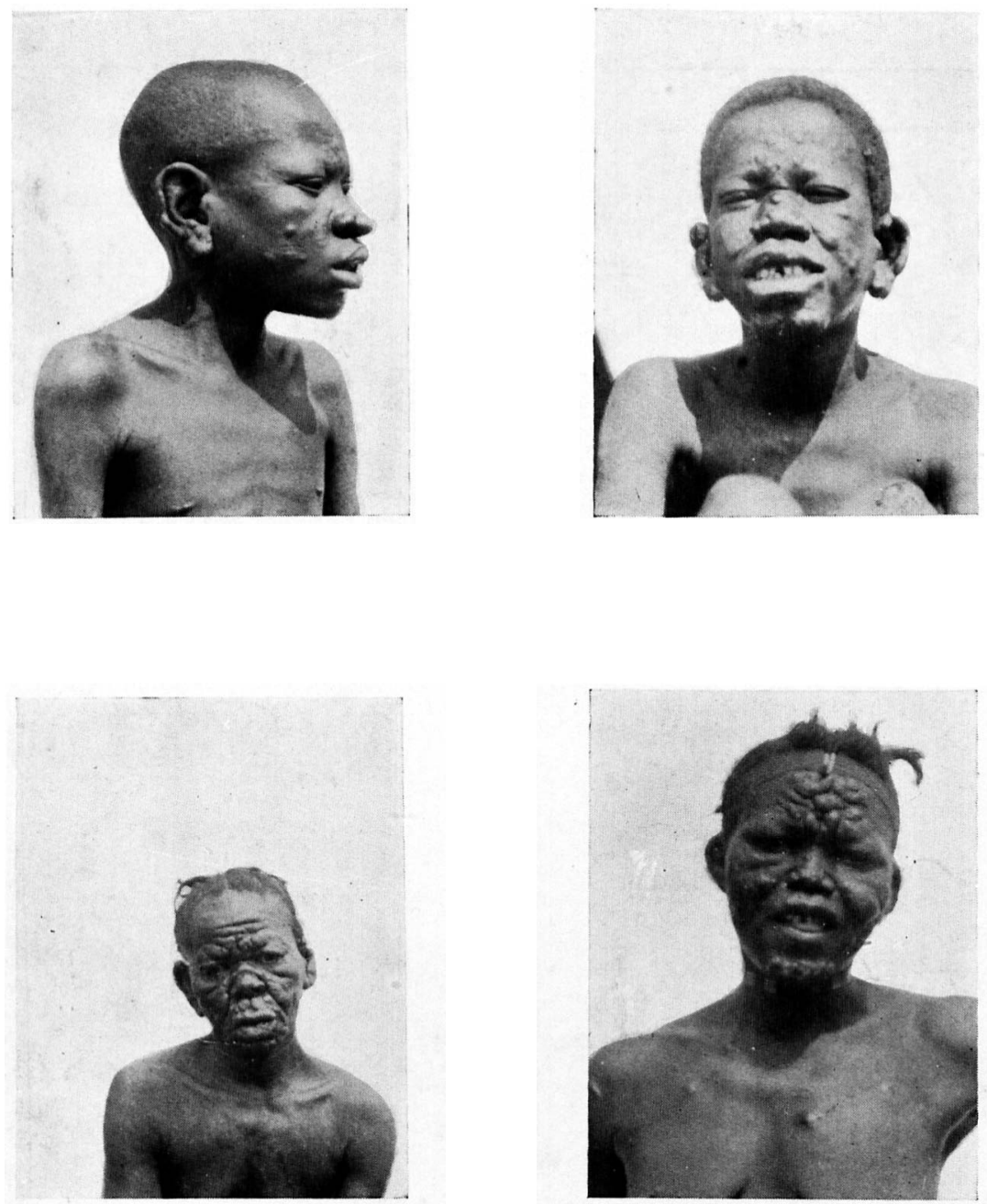

Typical Advanced Cases in the Bahr-el-Ghazal Province S. Sudan. 
Yambio and Tambura Districts, Southern Bahr-kL-Ghazal, Sudan.

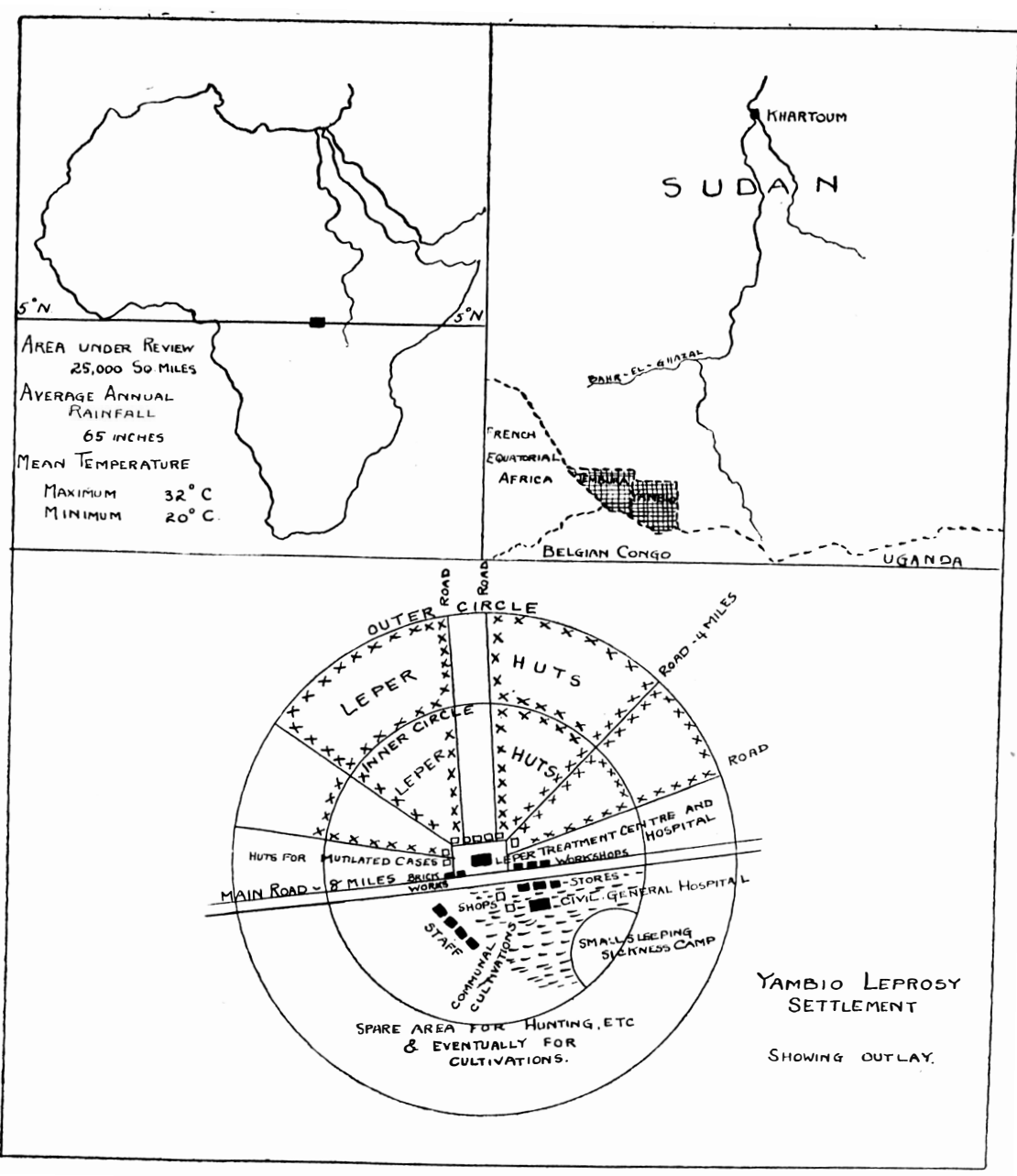


arrested cases ; in order to gain further evidence, however, the cases here are being divided into the following groups :-

1. Segregated in settlements under full treatment.

2. Segregated in settlements with no treatment, but enjoying the better conditions and food obtainable there, where every minor ailment can be attended to, and where a modicum of exercise in the shape of work is insisted upon.

3. Under observation in their homes, living their normal lives with no treatment but subject to regular examination.

4. Living their normal lives at home but receiving weekly treatment at an out-station dispensary.

\section{Conclusion.}

For the type of African leprosy encountered here, alepol does not appear to exert any potent beneficial action, and its disadvantages-pain and a tendency to thrombosis of veins-have yet to be overcome.

The jump from the dark depths of leprotic despair to the heights of the possibility of a positive cure, in the last few years has been remarkable, and productive of the most excellent results in that it has stimulated efforts to find a rational treatment, induced the necessary confidence in the minds of the patients, raised the enthusiasm and hopes of workers and made the finding of the very earliest cases possiblc. The rcbound from too much optimism to a more critical but still hopeful outlook will, we hope, promote the scarch for a still better treatment, which, when found, will be seized with avidity and tried out with enthusiasm by those of us who by the nature of their duties cannot devote their time to detailed research.

(I am indebted to the Director, Sudan Medical Service, for permission to publish these notes.) 